\title{
Influence of Quenching Temperature on Transformation Regularity of Reinforced Body for WC/steel Matrix Composites
}

\author{
Ning Zhang ${ }^{a}$, Sun Han ${ }^{b}$, Fu Jian ${ }^{\mathrm{c}}$ \\ Jiangsu Key Laboratory of Large Engineering Equipment Detection and Control, School of \\ Mechanical \& Electrical Engineering, Xuzhou Institute of Technology, Xuzhou, 221018, China

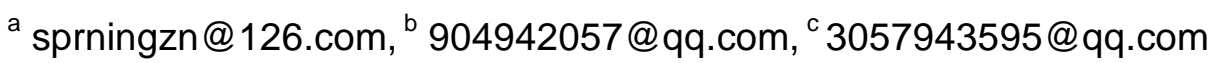

\begin{abstract}
Keywords: WC/steel matrix composites; quenching; transformation of reinforced body
\end{abstract}
Abstract. WC/steel matrix composites with WC particles of 150 mesh as reinforced body and $5 \mathrm{CrNiMo}$ steel as matrix, were prepared by electroslag melting and casting technology. The content of WC was $45 \%$. The influence of quenching temperature on the transformation regularity of reinforced body for WC/steel matrix composites was researched by the metallurgical microscope, scanning electron microscope, energy dispersive $\mathrm{X}$-ray spectroscopy, and $\mathrm{X}$ ray diffraction. The results show that with the increasing quenching temperature, the long strip and lump carbides dissolve signally, the network carbide further broke, the retained austenite volume continues to increase, a large number of small dots and rods proeutectoid carbides distribute in the matrix, while the change of the eutectic carbides with dendritic and fishbone shape is not obvious. Under the condition of this experiment, the optimum quenching temperature is $980^{\circ} \mathrm{C}$ to $1010^{\circ} \mathrm{C}$.

\section{Introduction}

Metal matrix composites are a relatively new material science developed in the 1960s. It is a composite made by metal or alloy as the matrix, and various reinforced material recombined fiber, whisker and grain. Particle Reinforced Metal Matrix Comoosite (PRMMC) not only has the superior toughness and plasticity of the steel matrix, but also has the characteristics of high hardness and high modulus of the reinforced particles. Due to the high melting point, density, the small ratio of strength, and the difficulty of manufacturing process, the study of steel matrix composites is less, and mainly focuses on aluminum matrix, magnesium matrix, titanium matrix and other lightweight composite materials, which are used in aerospace, aviation, automotive and other fields.

The particle reinforced technology used in the steel matrix composites seems to have a lot of advantages. So in this experiment, $5 \mathrm{CrNiMo}$ die steel was chosen as substrate material, and the WC particles as enhancement phase. The new type composite electroslag metallurgy manufacturing process was adopted to produce the WC particle reinforced steel matrix composite, then to study the influence of quenching temperature on the transformation regularity of reinforced body for $\mathrm{WC} /$ steel matrix composites.

\section{Experimental materials and methods}

The raw materials of steel matrix composite used by 150 mesh WC powders as hard phase, abandoned 5CrNiMo die steel as steel substrate. The waste $5 \mathrm{CrNiMo}$ die steel was made of a consumable electrode of composite materials in the intermediate frequency induction furnace, then put it into a one-armed beam vertical electrode electroslag furnace. The blank experiment material was made through adding configured $45 \%$ weight WC powder and electromagnetic stirring, then by forged and annealed treatment.

The middle part of the roll blank was cut into the size of $10 \mathrm{~mm} \times 10 \mathrm{~mm} \times 140 \mathrm{~mm}$ by DK7750 linear cutting machine, then coarse ground on a grinding machine. In order to prevent the material from oxidation and decarburization during the process of quenching treatment at these high temperatures, the prepared samples must be treated with oxidation and decarburization resistant coatings. The heat treatment process is shown in Fig.1, and the sample numbers are given in Table 1. 


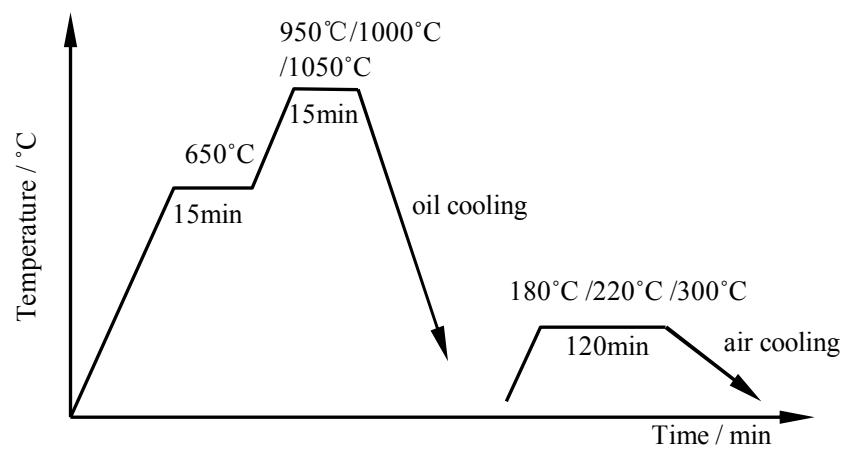

Fig.1 Diagram of heat treatment process

Table 1 Heat treatment process of composite material

\begin{tabular}{ccc}
\hline Sample & Number & Heat treatment process \\
\hline & A1 & Quench at $950^{\circ} \mathrm{C}+$ temper at $220^{\circ} \mathrm{C}$ \\
& A2 & Quench at $950^{\circ} \mathrm{C}+$ temper at $180^{\circ} \mathrm{C}$ \\
WC/steel Matrix & A3 & Quench at $1000^{\circ} \mathrm{C}+$ temper at $220^{\circ} \mathrm{C}$ \\
Composites & A4 & Quench at $1000^{\circ} \mathrm{C}+$ temper at $180^{\circ} \mathrm{C}$ \\
& A5 & Quench at $1050^{\circ} \mathrm{C}+$ temper at $220^{\circ} \mathrm{C}$ \\
& A6 & Quench at $1050^{\circ} \mathrm{C}+$ temper at $180^{\circ} \mathrm{C}$ \\
\hline
\end{tabular}

Samples, after heat treatment, were coarse ground on the grinding machine, and then finely ground by metallographic sandpaper, later polished to form mirror face shape using a polishing machine. The ground samples were corroded by $4 \%$ nital; their microstructure was analysed by OLYMPUS PMG3 metallographic microscope. The tissue morphology, phase and composition were measured by FEI Inspect S50 SEM, OXFORD X-act/INCA150 EDS, and BRUKER D8 Advance XRD.

\section{Experimental results and analysis}

Influence of quenching temperature on the transformation of WC reinforcement. The microstructures of $\mathrm{WC} /$ steel matrix composites in different quenching temperature and the same tempering temperature were shown in Fig.2. In Fig.2(a), A1 sample was quenched at $950^{\circ} \mathrm{C}$ and tempered at $220^{\circ} \mathrm{C}$, some parallel elongated structure, reticular tissue, and blocky organization distributed in the steel matrix which consisted of implicit tempered martensite, retained austenite and proeutectoid carbide. From EDS detection of point $\mathrm{A}$ and point $\mathrm{D}$ in Fig.3 and X ray diffraction analysis results, it can see that these elongated structure and reticular tissue, blocky organization are $\mathrm{Fe}_{3} \mathrm{~W}_{3} \mathrm{C}$ compound carbide and $\mathrm{M}_{7} \mathrm{C}_{3}$ carbide. Long strip carbides dissolved partially after quenching, the compound carbide rich in $\mathrm{W}$ dissolved and precipitated in point $\mathrm{B}$ of Fig.3. While in point $\mathrm{C}, \mathrm{W}$ content is $10.68 \mathrm{wt} \%$, the carbides mainly consist of Fe element. 

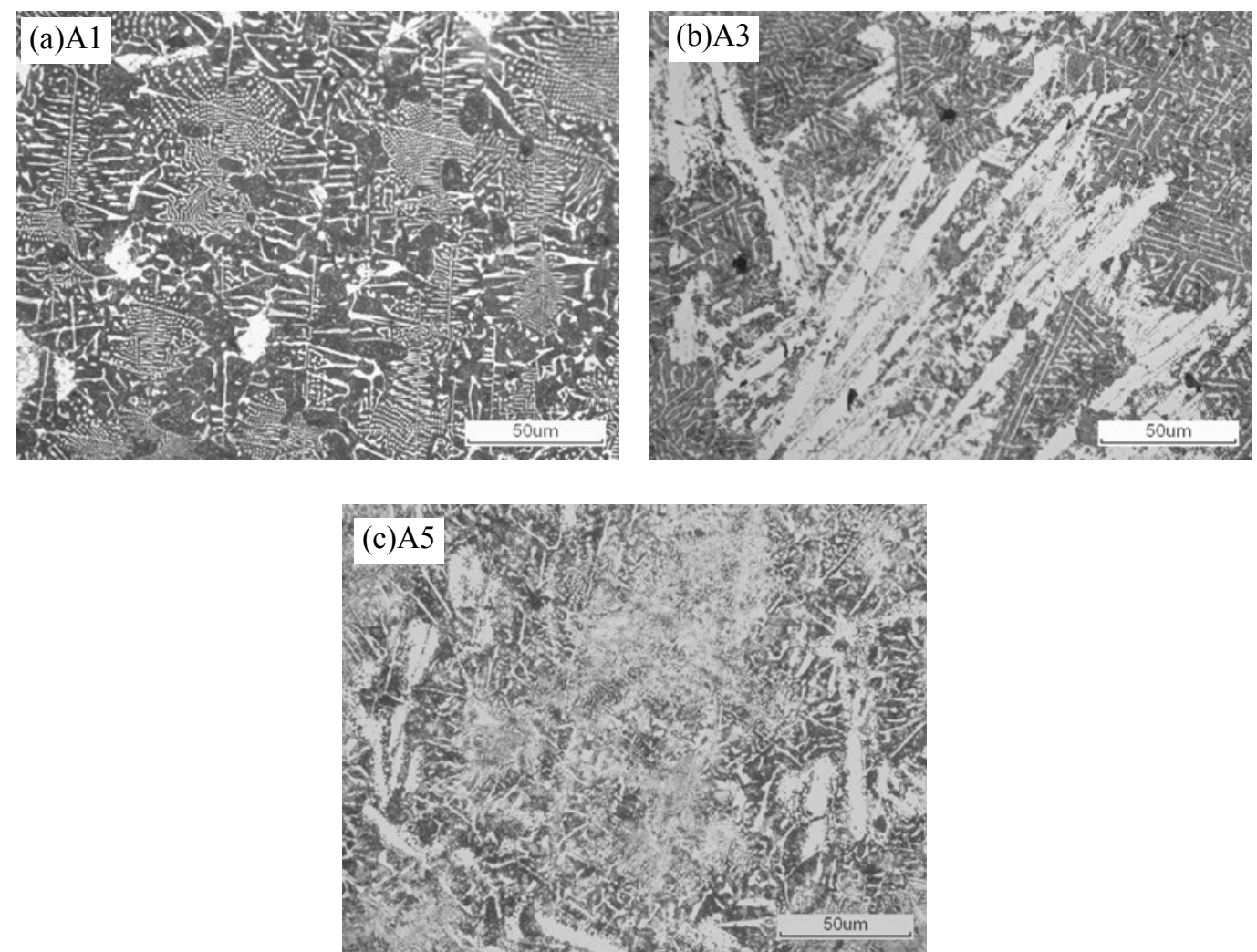

Fig.2 Microstructure of A1, A3 and A5 samples

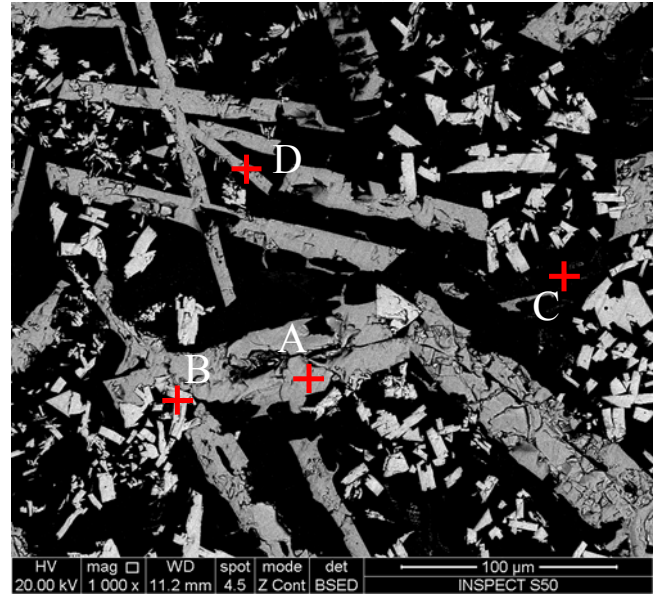

Fig.3 EDS point scanning of A3 sample

Table 2 The content of the elements of A3 sample analysed by EDS point scanning

\begin{tabular}{ccccccccc}
\hline \multirow{2}{*}{ Element } & \multicolumn{2}{c}{ A point } & \multicolumn{2}{c}{ B point } & \multicolumn{2}{c}{ C point } & \multicolumn{2}{c}{ D point } \\
\cline { 2 - 9 } & $\mathrm{Wt} \%$ & $\mathrm{At} \%$ & $\mathrm{Wt} \%$ & $\mathrm{At} \%$ & $\mathrm{Wt} \%$ & $\mathrm{At} \%$ & $\mathrm{Wt} \%$ & $\mathrm{At} \%$ \\
$\mathrm{C}$ & 8.97 & 49.11 & 12.61 & 60.67 & 14.90 & 47.34 & 11.98 & 56.91 \\
$\mathrm{Fe}$ & 22.36 & 26.33 & 15.94 & 16.49 & 68.84 & 47.05 & 22.20 & 22.67 \\
$\mathrm{~W}$ & 68.66 & 24.56 & 70.97 & 22.30 & 10.68 & 2.22 & 65.82 & 20.42 \\
$\mathrm{Cr}$ & - & - & 0.48 & 0.53 & 2.65 & 1.94 & - & - \\
$\mathrm{Mn}$ & - & - & - & - & 0.94 & 0.65 & - & - \\
$\mathrm{Mo}$ & - & - & - & - & 2.00 & 0.79 & - & - \\
\hline
\end{tabular}

In Fig.2(b), A3 sample was quenched at $1000^{\circ} \mathrm{C}$ and tempered at $220^{\circ} \mathrm{C}$, due to the high heating temperature, the carbide gradually dissolved, a large number of small point carbides precipitated in the steel matrix, the network carbide further broken, the long strip and lump carbides continued to dissolve. The fine dendritic structure could be seen, and a large number of retained austenite and proeutectoid carbides deposited in the matrix of the hidden Markov matrix. When the quenching temperature was low, the lump carbides could only dissolve within a certain point or at a few other points of the carbide, 
so the dissolution rate was very slow. Whlie when the quenching temperature was high, it would be dissolved from the inner and edge points of the carbide, the distribution of the dissolved surface was wide, so the dissolution rate accelerated.

In Fig.2(c), A5 sample was quenched at $1050^{\circ} \mathrm{C}$ and tempered at $220^{\circ} \mathrm{C}$, at this point the quenching temperature was very high, the long strip and lump carbides dissolved signally, the large number of net carbides broken and dissolved, the retained austenite volume continued to increase, a large number of small dots and rods proeutectoid carbides distributed in the matrix. The eutectic carbides with dendritic and fishbone shape were relatively stable, the dendrites grew along the preferred direction in symmetry. If the quenching temperature was low, the change was not obvious. But at $1050^{\circ} \mathrm{C}$, this kind of carbide could still maintain the original shape, the thermodynamic stability was very high.

With the increasing quenching temperature, the long strip and lump carbides dissolved signally, the network carbide further broken, it helped to improve the strength and toughness of the material. But the alloying elements enter into the steel matrix too much, which will make Ms point drop, increase retained austenite content, and reduce the overall hardness and wear resistance of the composite materials. It is necessary to select the appropriate quenching temperature. When the strength and the hardness meet the use requirements, appropriate increase of heating temperature will make the carbides dissolve and fragmentate, and obtain composite materials with excellent comprehensive properties. Under the condition of this experiment, the optimum quenching temperature is $980^{\circ} \mathrm{C}$ to $1010^{\circ} \mathrm{C}$.

\section{Conclusions}

(1) With the increasing quenching temperature, the long strip and lump carbides dissolve signally, the network carbide further broke, the retained austenite volume continues to increase, a large number of small dots and rods proeutectoid carbides distribute in the matrix, while the change of the eutectic carbides with dendritic and fishbone shape is not obvious.

(2) When the strength and the hardness meet the use requirements, appropriate increase of heating temperature will make the carbides dissolve and fragmentate, and obtain composite materials with excellent comprehensive properties. Under the condition of this experiment, the optimum quenching temperature is $980^{\circ} \mathrm{C}$ to $1010^{\circ} \mathrm{C}$.

(3) The scrap metal materials were produced as raw materials by the composite electroslag metallurgy technology, and the performance of the particle reinforced steel matrix composites improved greatly.

\section{Acknowledgements}

Supported by Natural Science Foundation of colleges and universities of Jiangsu Province in 2015(Grant No. 15KJB430030), General project of Xuzhou Institute of Technology (Grant No. XKY2014318).

\section{References}

[1] Ashok Kumar Srivastava, Karabi Das. The abrasive wear resistance of $\mathrm{TiC}$ and (TiC,W)Creinforced Fe-17Mn austenitic steel matrix composites[J]. Tribology International, 2010,43:944-950. [2] Nutthita Chuankrerkkul; Parinya Chakartnarodom. Fabrication of injection moulded 304L stainless steels reinforced with tungsten carbide particles, Materials Science Forum, 2012, 706-709, 638-642.

[3] Nutthita Chuankrerkkul, Parinya Chakartnarodom. Fabrication of Injection Moulded 304L Stainless Steels Reinforced with Tungsten Carbide Particles[J]. Materials Science Forum, 2012.

[4] Ning Zhang, Chuanhui Huang, Jinan Niu, et al. Influence of Heat Treatment Process to Advanced Steel Matrix Composites of Engineering Machinery Equipment. Advanced Materials Research, 2014,886:97-100. 
[5] Ning Zhang,Chunhong Zhang, Juli Li. Research of in-situ synthesis Ti(C、N)-WC particle reinforced Ni60A composite coating by argon arc cladding[J]. Journal of Xuzhou Istitute of Technology, 2015, 30(1): 47-51.

[6] Dash, K; Panda, S.; Ray, B.C. Process and progress of sintering behavior of Cu-Al2O3 composites, Emerging Materials Research, 2013, 2(1), 32-38.

[7] Dekun Zhang, Junjie Duan. On the Siding-rolling Friction and Wear Properties of Point Contact Friction Couple Between GCr15 Steel Ball and GCr15 Steel Disc[J]. Journal of Xuzhou Istitute of Technology, 2014, 29 (4): 7-12. 